\title{
Bone morphogenic protein signaling in spinal cord injury
}

\author{
Nadia Al-Sammarraie, Swapan K. Ray \\ Department of Pathology, Microbiology, and Immunology, University of South Carolina School of Medicine, Columbia, SC \\ 29209, USA. \\ Correspondence to: Prof. Swapan K. Ray, Department of Pathology, Microbiology, and Immunology, University of South Carolina \\ School of Medicine, 6439 Garners Ferry Road, Columbia, SC 29209, USA. E-mail: swapan.ray@uscmed.sc.edu
}

How to cite this article: Al-Sammarraie N, Ray SK. Bone morphogenic protein signaling in spinal cord injury. Neuroimmunol Neuroinflammation 2021;8:53-63. http://dx.doi.org/10.20517/2347-8659.2020.34

Received: 24 Apr 2020 Accepted: 30 Apr 2020 Fisrt online: 4 Sep 2020 Published: 21 Mar 2021

Science Editor: Gang Zhao Copy Editor: Jing-Wen Zhang Production Editor: Tian Zhang

\begin{abstract}
Spinal cord injury $(\mathrm{SCl})$ is a debilitating injury that results from traumatic or non-traumatic insults to the spinal cord, causing significant impairment of the patient's activity and quality of life. Bone morphogenic proteins (BMPs) are a group of polyfunctional cytokines belonging to the transforming growth factor beta superfamily that regulates a wide variety of cellular functions in healthy and disease states. Recent studies suggest that dysregulation of BMP signaling is involved in neuronal demyelination and death after traumatic $\mathrm{SCl}$. The focus of this article is to describe our current understanding of the role of BMP signaling in the regulation of cell fate, proliferation, apoptosis, autophagy, and inflammation in traumatic $\mathrm{SCl}$. First, we will describe the expression of BMPs and pattern of BMP signaling before and after traumatic $\mathrm{SCl}$ in rodent models and in vitro. Next, we will discuss the role of BMP in the regulation of neuronal and glial cell differentiation, survival, functional recovery from traumatic $\mathrm{SCl}$, and the gap in knowledge in this area that requires further investigation to improve $\mathrm{SCl}$ prognosis.
\end{abstract}

Keywords: Spinal cord injury, bone morphogenic protein, apoptosis, proliferation, autophagy, differentiation, inflammation

\section{INTRODUCTION}

Spinal cord injury (SCI) can be either traumatic or non-traumatic damage to the spinal cord and has a peak prevalence of approximately $906-1800$ cases per million people in the United States ${ }^{[1-3]}$. SCI usually causes complete or partial motor and sensory neurological deficits with deleterious outcomes ${ }^{[4]}$. Traumatic SCI can be caused by major trauma to the spinal cord following road traffic accidents, falls in the elderly, and violent and sport-related injuries ${ }^{[1,3]}$. Non-traumatic SCI usually result from ischemic-reperfusion

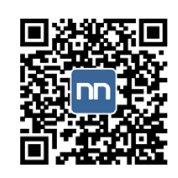




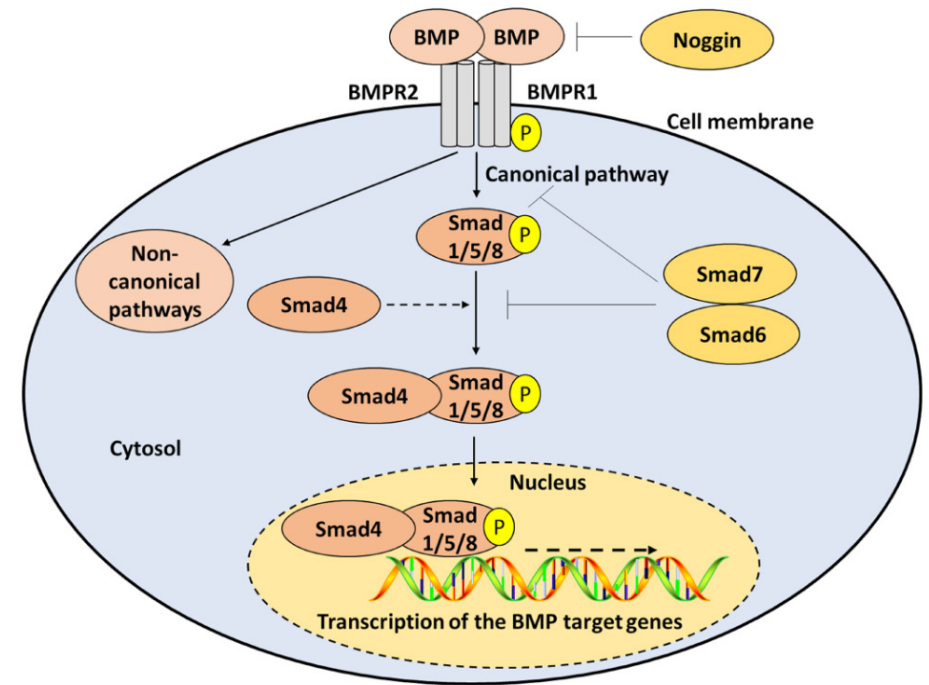

Figure 1. Molecular components and pathways of BMP signaling. The BMP signaling is initiated by the binding of BMP ligands to BMPR1 and BMPR2. In the canonical pathway, BMP receptors phosphorylate Smad1/5/8, which can bind to Co-Smad4 and are translocated to the nucleus to regulate the expression of target genes. In the non-canonical pathways, BMP receptors activate non-Smad pathways. Termination of BMP signaling is achieved by noggin, Smad6, and/or Smad7. BMP: bone morphogenic protein; BMPR: BMP receptor

injury, congenital malformations, degenerative diseases, malignancy, autoimmune diseases, or infections in the spinal $\operatorname{cord}^{[2,5,6]}$. Traumatic SCI is a devastating neurological condition characterized by both acute and chronic phases of progressive spinal cord damage that involve neuroinflammation, oligodendrocytes loss, neuronal loss, demyelination, and reactive astrogliosis with scar formation ${ }^{[7,8]}$. The acute phase is characterized by oligodendrocyte death and demyelination, reactive astrocyte proliferation, axonal swelling, and acute inflammatory cell infiltration ${ }^{[9,10]}$. The chronic phase is characterized by chronic infiltration of inflammatory cells, partial neuronal regrowth and remyelination, and glial scar establishment ${ }^{[10,11]}$. The upregulation of detrimental factors and pathways cause progressive pathogenesis leading to the activation of cysteine proteases (calpains and caspases) for neuronal and glial cell death, and declining neurological function (motor and sensory) in both acute and chronic traumatic $\mathrm{SCI}^{[12,13]}$. Current research is mostly focused on traumatic SCI for understanding of its pathogenesis and developing effective new therapeutic strategies. The main goals in developing new therapies for traumatic SCI are to minimize neural cell loss and prevent glial scar formation to promote remyelination and functional recovery ${ }^{[8,14]}$.

Bone morphogenetic proteins (BMPs) are a group of approximately 15 growth regulating polyfunctional cytokines that belong to the transforming growth factor beta (TGF $\beta$ ) superfamily and are widely expressed in both the intact and injured spinal cord ${ }^{[15,16]}$. Signal activation and transduction include the binding of BMP cytokines to BMP receptor 1 (BMPR1A, BMPR1B, or ActR-1A) and BMP receptor 2 complex, followed by phosphorylation and activation of Smad1/5/8 intracellular receptor regulated proteins or R-Smads ${ }^{[15,17,18]}$. Smad1/5/8 proteins then bind to the common Smad4 or the Co-Smad4 to form a complex, which is translocated to the nucleus to regulate transcription of BMP-targeted genes in a context dependent manner ${ }^{[15,17,18]}$. Inhibition of signaling is usually achieved via the activation and competitive binding of Smad6, Smad7, and noggin inhibitory proteins. Smad6 and Smad7 inhibit the interaction between BMP receptors and R-Smads and/or the interaction between the R-Smads and the common Smad $4{ }^{[19-21]}$. Noggin inhibitory proteins bind with high affinity to BMP ligand proteins and prevent their association with their receptors $^{[22]}$ [Figure 1].

Growing evidence from rodent models of $\mathrm{SCI}^{[16,23]}$ show that BMP ligands and receptors are expressed in the intact spinal cord and are drastically upregulated post-injury. This is summarized in Table 1. 
Table 1. Expression of BMP signaling components before and after $\mathrm{SCl}$ in rodent models

\begin{tabular}{|c|c|c|c|}
\hline $\begin{array}{l}\text { BMP signaling } \\
\text { component }\end{array}$ & $\begin{array}{c}\mathrm{SCl} \\
\text { model }\end{array}$ & Outcomes & Ref. \\
\hline \multirow[t]{12}{*}{ BMP ligands } & Rats & $\begin{array}{l}\text { BMP7 mRNA was mildly expressed in glial cells in intact spinal cord but markedly expressed in } \\
\text { glial cells and motoneurons post-SCl }\end{array}$ & {$[27]$} \\
\hline & Rats & $\begin{array}{l}\text { BMP2/4 mRNA was mildly expressed in intact spinal cord but markedly expressed in } \\
\text { oligodendrocytes, astrocytes, and microglia surrounding the damaged site post-SCI }\end{array}$ & [23] \\
\hline & Mice & $\begin{array}{l}\text { BMP2, 4, and } 7 \text { levels were increased in neurons, microglia, oligodendrocytes, and NSCs post- } \\
\text { SCI, which enhanced astrocyte proliferation. BMP4 promoted differentiation of astrocytes and } \\
\text { inhibited differentiation of neurons and oligodendrocytes }\end{array}$ & [37] \\
\hline & Rats & $\begin{array}{l}\text { BMP2 and } 4 \text { levels were increased post-SCI and promoted differentiation of the engrafted OPCs } \\
\text { cells into astrocytes }\end{array}$ & {$[40]$} \\
\hline & Mice & $\begin{array}{l}\text { BMP7 expression was increased after } \mathrm{SCl} \text { and further augmented after agmatine treatment, } \\
\text { leading to reduced collagen scar formation and improved } \mathrm{BBB} \text { score post-SCI }\end{array}$ & [30] \\
\hline & Rats & BMP4 expression was increased in astrocytes cultured from injured thoracic spinal cord & [36] \\
\hline & Rats & BMP2/4 expression was increased after $\mathrm{SCl}$ and associated with low $\mathrm{BBB}$ scores & [29] \\
\hline & Rats & $\begin{array}{l}\text { BMP7 was expressed in glial cells of the intact spinal cord and increased in glial cells and } \\
\text { motoneurons after } \mathrm{SCl}\end{array}$ & [27] \\
\hline & Mice & BMP2 was slightly expressed in intact spinal cord and markedly increased post-SCI & [38] \\
\hline & Mice & $\begin{array}{l}\text { BMP4 level was increased in neurons of gray and white matter and ependyma cells near the } \\
\text { damaged site post-SCl }\end{array}$ & [28] \\
\hline & Rats & BMP4 was overexpressed after acute $\mathrm{SCl}$ & [57] \\
\hline & Rats & BMP2, 3, 4, 5, 7, 9, 12, and 13 were expressed in intact spinal cord & {$[16]$} \\
\hline BMP receptors & Rats & BMPR1A and BMPR2 expression levels were increased in neurons post-SCI & [23] \\
\hline BMP antagonists & Rats & Noggin was minimally expressed in intact spinal cord & {$[16]$} \\
\hline Canonical pathway & Mice & $\begin{array}{l}\text { p-Smad1, 5, and } 8 \text { were activated in neurons, oligodendrocytes, OPCs, astrocytes, and NSCs post- } \\
\text { SCl }\end{array}$ & [37] \\
\hline
\end{tabular}

BMP: bone morphogenic protein; SCl: spinal cord injury; OPCs: oligodendrocyte precursor cells; NSCs: neural stem cells; BBB: Basso, Beattie, and Bresnahan; BMPR: BMP receptor

Table 2. Effects of BMP treatment on neuronal and non-neuronal cells in $\mathrm{SCl}$ in in vitro models

\begin{tabular}{|c|c|c|c|}
\hline $\begin{array}{l}\text { BMP signaling } \\
\text { component }\end{array}$ & Treatment & Outcomes & Ref. \\
\hline \multirow[t]{4}{*}{ BMP ligands } & BMP7 & BMP7 inhibited tumor necrosis factor $\alpha$-mediated oligodendrocyte death & [56] \\
\hline & BMP7 & BMP7 inhibited glutamate induced neuronal cell death & [24] \\
\hline & BMP4 & $\begin{array}{l}\text { In vitro culture of NSCs in the presence of BMP4 resulted in amelioration of oligodendrocyte } \\
\text { differentiation and increase in astrocyte differentiation. Smad1 and } 5 \text { were activated in } \\
\text { response to BMP4 treatment of NSCs }\end{array}$ & [25] \\
\hline & BMP7 & Noggin expressing OPCs treated with BMP7 showed less astrocytic differentiation & [16] \\
\hline \multirow[t]{5}{*}{ BMP antagonists } & Noggin & $\begin{array}{l}\text { Noggin treatment reduced astrocyte numbers. Inhibition of BMP4 using noggin attenuated } \\
\text { differentiation of NSCs into astrocytes }\end{array}$ & [37] \\
\hline & Noggin & Noggin treatment of OPCs partially reduced astrocytic differentiation & [40] \\
\hline & Noggin & $\begin{array}{l}\text { Noggin treatment reduced differentiation of OPCs into astrocytes in astrocyte conditioning } \\
\text { media. p-Smad1, } 5 \text {, and } 8 \text { levels were increased in OPCs in astrocyte conditioning media } \\
\text { compared to control. OPCs cultured in astrocyte conditioning media predominantly } \\
\text { differentiated into astrocytes }\end{array}$ & [36] \\
\hline & $\begin{array}{l}\text { Noggin and } \\
\text { LDN193189 }\end{array}$ & $\begin{array}{l}\text { Treatment attenuated BMP4 induced activation of caspase- } 3 \text { for cell death in neurons and } \\
\text { oligodendrocytes post-SCl }\end{array}$ & [57] \\
\hline & Noggin & $\begin{array}{l}\text { Noggin treatment reduced astrocytic differentiation and increased the differentiation of NSCs } \\
\text { into oligodendrocytes }\end{array}$ & [25] \\
\hline
\end{tabular}

BMP: bone morphogenic protein; SCI: spinal cord injury; OPCs: oligodendrocyte precursor cells; NSCs: neural stem cells

Furthermore, in vitro studies ${ }^{[24,25]}$ extensively elucidated the protective and deregulatory role of BMP components in a variety of cellular events on both neuronal and non-neuronal cells, which are summarized in Table 2. Most of these studies focused mainly on the level of expression of BMP signaling proteins and the resultant cellular damage, describing only limited knowledge on molecular regulation and downstream targets. This article will focus mainly on the role of different BMP ligands and receptors on neuronal and glial cell differentiation, neuroinflammation, cell death, and autophagy in the in vivo and in vitro models 


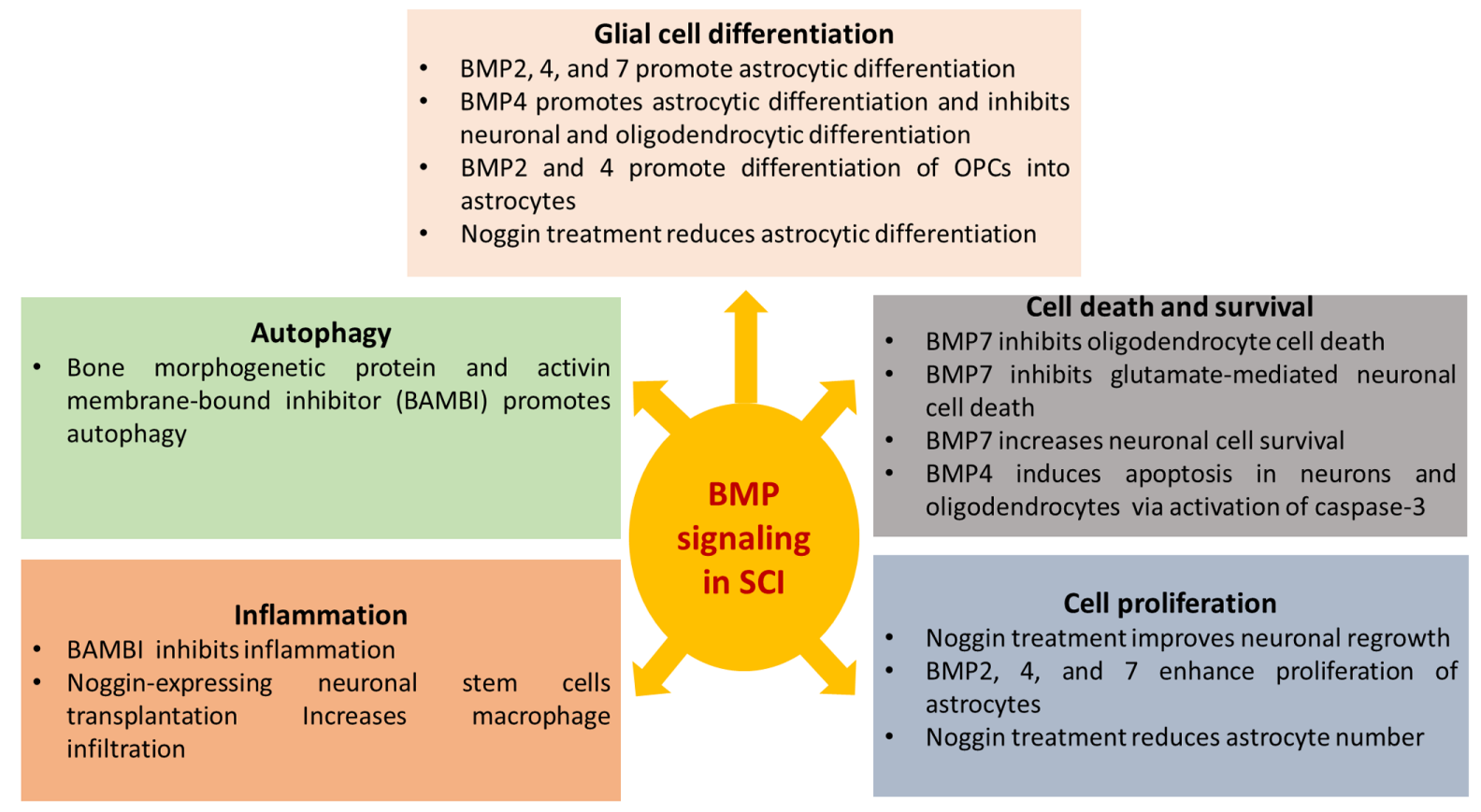

Figure 2. Cellular manifestations of $\mathrm{BMP}$ signaling in $\mathrm{SCl}$. This diagram illustrates the in vitro and in vivo effects of activation or inhibition of BMP signaling on neuronal and/or glial cell proliferation, differentiation, survival, apoptosis, autophagy, and inflammation in SCI. BMP: bone morphogenic protein; SCI: spinal cord injury; BAMBI: BMP and activin membrane-bound inhibitor; OPCs: oligodendrocyte precursor cells

of traumatic SCI, which are summarized in Figure 2. Next, we will discuss the gap in knowledge in this area and suggest future studies for further understanding of the role of BMP signaling in pathogenesis in traumatic SCI that remains largely elusive.

\section{EXPRESSION OF BMP LIGANDS, RECEPTORS, AND SMAD AND NON-SMAD SIGNALING IN}

\section{SPINAL CORD BEFORE AND AFTER INJURY, AND THEIR ASSOCIATION WITH FUNCTIONAL RECOVERY IN SCI}

Studies in rodent models of SCI have shown that BMP ligands and receptors are expressed in intact spinal cord and their expression are further increased following SCI. BMP2, 3, 4, 5, 7, 9, 12, and 13 and the BMP receptors $1 \mathrm{~A}, 1 \mathrm{~B}$, and 2 are minimally expressed in uninjured spinal cord ${ }^{[16,23,26]}$. However, after SCI, the expression of BMP ligands and their receptors are increased considerably in neuronal and glial cells in spinal cord and exert diverse cellular effects ${ }^{[23,27]}$. The increase in $\mathrm{BMP} 2,4$, and 7 expression levels are amongst the most studied BMP ligands after SCI. Expression levels of the ligands and the downstream canonical pathway and non-canonical pathways were markedly increased in response to SCI. Chen et al. ${ }^{[28]}$ studied the expression of $\mathrm{BMP} 4$ and other signaling molecules critical for neuronal development in SCI in mice. This study found that BMP4 was upregulated after SCI in the neurons of the gray and white matter and ependymal cells (a type of glial cells known to produce cerebrospinal fluid and act as reservoir of neurodegeneration) surrounding the SCI lesion ${ }^{[28]}$. Setoguchi et al. ${ }^{[27]}$ studied the expression of BMP7 before and after acute SCI in rat model ${ }^{[27]}$. This study found that BMP7 was expressed in glial cells at low levels before injury but its expression was markedly increased in glial cells and expression occurred in motoneurons after $\mathrm{SCI}^{[27]}$ [Table 1].

Cui et al. ${ }^{[29]}$ conducted a study to examine the changes in expression of BMP2 and 4 in a rat model of SCI. This study found increases in expression of both BMP2 and 4 after SCI, which correlated with low 
Table 3. Therapeutic and genetic targeting of BMP signaling in $\mathrm{SCl}$ in in vivo models

\begin{tabular}{|c|c|c|c|}
\hline Treatment & $\mathrm{SCl}$ model & Effects & Ref. \\
\hline BMP7 & Rats & $\begin{array}{l}\text { BMP7 promoted neuroprotection via an increase in the number of surviving neurons, in } \\
\text { part, via increased p38 non-canonical signaling }\end{array}$ & {$[24]$} \\
\hline Agmatine & Mice & $\begin{array}{l}\text { It augmented BMP7 expression, reduced collagen scar formation, and improved BBB } \\
\text { scores }\end{array}$ & [30] \\
\hline Agmatine & Mice & $\begin{array}{l}\text { It reduced neuronal cell death and scar formation, leading to improved locomotive } \\
\text { function. This effect was achieved, in part, via increased expression of BMP2/7 in } \\
\text { neurons and oligodendrocytes, and decreased expression of BMP4 in the damaged site }\end{array}$ & {$[31]$} \\
\hline $\begin{array}{l}\text { Conditional deletion of } \\
\text { astrocytic BMPR1A and 1B }\end{array}$ & Mice & $\begin{array}{l}\text { Knockouts of astrocytic BMPR1A cause reduction in astrocytic hypertrophy, decrease in } \\
\text { axonal density, and enhancement of the inflammatory response. In contrast, knockouts } \\
\text { of astrocytic BMPR1B increase astrocytic hypertrophy and reduce lesion size and glial } \\
\text { scar formation post-SCI }\end{array}$ & {$[26]$} \\
\hline $\begin{array}{l}\text { Transplantation of OPCs } \\
\text { expressing BMPR1A, 1B, } \\
\text { and } 2\end{array}$ & Rats & $\begin{array}{l}\text { Transplantation of OPCs expressing (BMPR1A, 1B, and } 2 \text { ) into rat spinal cord led to their } \\
\text { differentiation into astrocytes }\end{array}$ & [40] \\
\hline $\begin{array}{l}\text { Administration of AAV } \\
\text { vector encoding BMP4 }\end{array}$ & Mice & $\begin{array}{l}\text { Intra-thecal administration of AAV vector encoding BMP4 led to Smad1 activation in } \\
\text { dorsal motoneuron and increased axonal regrowth after SCl }\end{array}$ & [42] \\
\hline $\begin{array}{l}\text { Conditional knockout of } \\
\beta 1 \text {-integrin in ependymal } \\
\text { stem cells }\end{array}$ & Mice & $\begin{array}{l}\text { Conditional knockout of } \beta 1 \text {-integrin in ependymal stem cells increased the movement of } \\
\text { BMPR1B into lipid rafts while enhancing BMP signaling (canonical and non-canonical) } \\
\text { and glial scar formation }\end{array}$ & [39] \\
\hline Noggin & Rats & $\begin{array}{l}\text { Administration of recombinant mouse noggin intra-thecally improved locomotive } \\
\text { function post- } \mathrm{SCl} \text { and enhanced axonal regrowth }\end{array}$ & [23] \\
\hline Noggin & Rats & Noggin treatment reduced BMP2/4 expression and improved motor scored post-SCI & [29] \\
\hline $\begin{array}{l}\text { Transplantation of } \\
\text { Smad6, Smad7, or noggin } \\
\text { expressing NPCs }\end{array}$ & Mice & $\begin{array}{l}\text { It promoted differentiation of NPCs into oligodendrocytes and neurons but inhibited } \\
\text { their differentiation into astrocytes, leading to improvement of BBB scores in mice post- } \\
\mathrm{SCl}\end{array}$ & [38] \\
\hline $\begin{array}{l}\text { Transplantation of noggin } \\
\text { expressing neuronal stem } \\
\text { cells }\end{array}$ & Rats & $\begin{array}{l}\text { It led to macrophage infiltration and widening of lesion size, but prevented astrocytic } \\
\text { differentiation post-SCl }\end{array}$ & {$[16]$} \\
\hline BAMBI & Rats & Overexpression of BAMBI inhibited inflammation and promoted autophagy post-SCI & [54] \\
\hline BMP2 & Rats & $\begin{array}{l}\text { Intra-thecal administration of rhBMP2 resulted in increases in expression of } \mathrm{p} \text {-Smad1, } 5 \text {, } \\
\text { and } 8 \text { in most spinal cord cell types }\end{array}$ & [32] \\
\hline
\end{tabular}

BMP: bone morphogenic protein; SCl: spinal cord injury; OPCs: oligodendrocyte precursor cells; NSCs: neural stem cells; BBB: Basso, Beattie, and Bresnahan; BMPR: BMP receptor; BAMBI: BMP and activin membrane-bound inhibitor; AAV: adeno-associated virus

Basso, Beattie, and Bresnahan (BBB) motor assessment scores when compared to controls ${ }^{[29]}$. Furthermore, they found that inhibition of BMP signaling using noggin treatment was able to improve BBB scores when compared to the untreated group after hemisection $\mathrm{SCI}^{[29]}$. Matsuura et al. ${ }^{[23]}$ studied the changes in expression of levels of BMP2 and 4 and the BMP receptor 2 in rats after SCI, and the effect of noggin treatment on recovery from SCI. They found that BMP2 and 4 and the BMP receptor 2 were slightly expressed in intact spinal cord and expression levels were further increased after SCI. Moreover, noggin treatment was able to improve locomotive function after SCI when compared to the non-treated SCI group $^{[23]}$. Besides, several treatments with endogenous BMP components or recombinant BMP protein resulted in neuroprotective effects and improved locomotive function by modulating BMP signaling ${ }^{[30-32]}$. Kim et al. ${ }^{[30]}$ compared the effects of agmatine, an endogenous protein with neuroprotective effects, on scar formation and functional recovery after SCI in mice. This study found that agmatine reduced scar size and improved BBB scores, in part, by increasing expression of $\mathrm{BMP}^{[30]}$. Park et al. ${ }^{[31]}$ showed that intraperitoneal agmatine treatment in a mice model of SCI was associated with increased expression of $\mathrm{BMP} 2$ and 7 in neurons and oligodendrocytes while expression of BMP4 in astrocytes and oligodendrocytes surrounding the damage site was reduced. The treatment resulted in improvement of locomotive function, inhibited neuronal death, and reduced scar size ${ }^{[31]}$. Similarly, Dmitriev et al. ${ }^{[32]}$ studied the effect of intrathecal administration of $\mathrm{rhBMP} 2$ on expression of $\mathrm{p}-\operatorname{Smad}_{1}, 5$, and 8 within the cells of the spinal cord after SCI in rats. The study found significant activation of $\mathrm{p}$-Smad1, 5, and 8 in all neuronal cells, glial cells, and fibroblasts, which might affect recovery from SCI following rhBMP2 treatment [Table 3].

\section{ROLE OF BMP SIGNALING IN DIFFERENTIATION OF GLIAL CELLS AFTER SCI}

Astrocytes, oligodendrocytes, ependymal cells, and microglia are non-neuronal heterogenous cell types that maintain spinal cord integrity, homeostasis, and myelination ${ }^{[33]}$. Marked increase in astrocyte differentiation 
was observed in response to SCI, which contributed to glial scar formation in SCI tissue ${ }^{[34]}$. On one hand, glial scar provides protective mechanisms to limit the lesion size after SCI; on the other hand, it leads to deleterious effects by the inhibition of axonal regeneration ${ }^{[34,35]}$. Recent studies suggest that BMP signaling promotes differentiation of neuronal stem cells (NSCs) and oligodendrocyte precursor cells (OPCs) into astrocytes predominantly ${ }^{[36-38]}$. Wang et al ${ }^{[36]}$ studied the effect of the microenvironment created by reactive astrocytes on the differentiation of OPCs after SCI in rats. They found that SCI increased the expression of $\mathrm{BMP}_{4}$ in astrocytes isolated from the site of injury, and it further released $\mathrm{BMP}_{4}$ in their conditioning media. They also found that in vitro culture of OPCs in astrocytes-derived conditioning media activated Smad1, 5, and 8, which led to differentiation of a significant number of OPCs into astrocytes, while inhibiting differentiation of oligodendrocytes ${ }^{[36]}$.

In contrast, noggin treatment reduced astrocytic differentiation and increased oligodendrocytic differentiation ${ }^{[36]}$. Similarly, Xiao et al. ${ }^{[37]}$ conducted a study to test the effect of BMP signaling on the differentiation of NSCs after SCI in mice. This study found that BMP2, 4, and 7 were expressed in intact spinal cord and their expression was further increased after SCI in the following cell types: neurons, NSCs, microglia, and oligodendrocytes, but not in astrocytes ${ }^{[37]}$. They also found that the expression of phosphorylated Smad1, 5, and 8 were increased after SCI in the above cell types, OPCs, and astrocytes ${ }^{[37]}$. Furthermore, they found that BMP4 was highly expressed in neutrospheres (free-floating clusters of neural stem cells) cultured from the spinal cord and it promoted astrocytic differentiation from NSCs, while inhibition of BMP signaling using noggin treatment reduced astrocytic differentiation ${ }^{[37]}$. Setoguchi et al. ${ }^{[38]}$ examined the effect of BMPs on the differentiation of transplanted NPCs in vitro and after SCI in mice. This study found that BMP2 was expressed in the spinal cord before injury and was upregulated drastically after $^{[38]}$. They also found that BMP2 and 7 promoted the differentiation of NPCs to astrocytes in vitro, while the inhibition of BMP signaling using Smad6, Smad7, or noggin overexpressing NPCs resulted in the differentiation of NPCs into neuronal cells and inhibited the differentiation of NPCs into astrocytes ${ }^{[38]}$. Similarly, transplanting the above-modified NPCs into a mice model of SCI resulted in improvement of the motor scores with inhibition of astrocytic differentiation and promotion of neuronal and oligodendrocytic differentiations in vivo ${ }^{[38]}$. Together, these studies imply that targeting BMP signaling could be beneficial for ameliorating astrocytic scar formation, and for enhancing oligodendrocytic differentiation for remyelination after SCI.

In addition, North et al ${ }^{[39]}$ showed that the conditional deletion of $\beta 1$ integrin from ependymal stem cells resulted in an increase in their differentiation into astrocytes, which could promote glial scar formation after SCI and reduce BBB motor scores in SCI mice, which were found to be associated with increases in canonical (Smad1/5/8) and non-canonical (p38) signaling. Furthermore, Song et al. ${ }^{[25]}$ found that BMP4 treatment of NSCs in culture promoted astrocytic differentiation via activation of Smad1/5/8, while noggin treatment resulted in reduction of astrocytic differentiation and an increase in oligodendrocytic differentiation in vitro. In contrast, Enzmann et al. ${ }^{[16]}$ showed that the intra-thecal transplantation of noggin overexpressing NSCs or progenitor cells was unable to restrict astrocytic differentiation in rats after SCI, suggesting additional regulatory mechanisms were controlling astrocytic differentiation.

Studies also showed that the expression of BMP receptors was increased after SCI, particularly affecting astrocytic hypertrophy (an astrocyte grown bigger than its normal size to adapt to changes) and differentiation. Astrocytes play both physiological and pathological roles after traumatic SCI, which triggers an initial astroctytic hypertrophy and subsequently, an astrocytic hyperplasia. In astrocytic hypertrophy, astrocytes are reactive with bigger bodies, thicker processes, and overexpression of their intermediate filament proteins such as glial fibrillary acidic protein and vimentin to help repair the blood-brain barrier and reduce the spread of inflammatory cells at the site of SCI. On the other hand, in astrocytic hyperplasia, astrocytes increase their numbers around the injury site and produce much finer processes to contribute to 
the development of the glial scar that becomes an impediment to axonal regeneration after SCI. Conditional deletion of astrocytic BMPR1A in mice has adverse effects on recovery after SCI via impairing astrocytic hypertrophy, reducing axonal density, and fostering inflammation ${ }^{[26]}$. In contrast, conditional deletion of astrocytic BMPR1B has more beneficial effects by increasing the number of hypertrophied astrocytes, attenuation of the glial scar, and diminishing lesion size in mice after $\mathrm{SCI}^{[26]}$. In addition, expression of BMPR1A, 1B, and 2 in OPCs that were transplanted into rat spinal cord predominantly promoted their differentiation into astrocytes ${ }^{[40]}$. Similarly, culture of OPCs in the presence or absence of $\mathrm{BMP}_{2} / 4$ and noggin showed that BMP treatment increased their differentiation into astrocytes while noggin treatment enhanced it ${ }^{[40]}$.

\section{ROLE OF BMP SIGNALING IN AXONAL GROWTH AND GLIAL CELL PROLIFERATIONS AFTER $\mathrm{SCl}$}

Reactive astrogliosis (also known simply as astrogliosis or astrocytosis) and neuronal regrowth occur in response to the loss of glial cells and neurons after SCI to partially promote healing of tissue damage and attempt neuronal recovery ${ }^{[10,41]}$. Recent studies suggest that BMP signaling causes astrocytic proliferation and neuronal growth after SCI ${ }^{[23,37,42]}$. Parikh et al. ${ }^{[42]}$ studied whether Smad1 activation could have a beneficial effect on axonal regeneration in mice after SCI. BMP4 overexpression in dorsal motoneurons was achieved by the intra-thecal administration of viral vectors overexpressing BMP4 in mice after SCI ${ }^{[42]}$. The results show activation of Smad 1 in dorsal neurons, which is associated with improving axonal growth after $\mathrm{SCI}^{[42]}$. The administration of recombinant mouse noggin intra-thecally improved locomotive function and increased axonal regrowth after $\mathrm{SCI}^{[23]}$. Xiao et al. ${ }^{[37]}$ found that the levels of BMP2, 4, and 7 expression were all increased in neurons, microglia, oligodendrocytes, and NSCs after SCI, which enhanced astrocytic proliferation, while noggin treatment diminished astrocyte numbers.

\section{ROLE OF BMP SIGNALING IN AUTOPHAGY AFTER SCI}

Autophagy or "self-eating" is a central molecular mechanism that regulates tissue homeostasis in health and disease ${ }^{[43]}$. Autophagy is characterized by direct or indirect lysosomal degradation of damaged mitochondria, misfolded proteins, and other cellular debris for recycling to maintain energy metabolism in response to stressful stimuli ${ }^{[43]}$. Macroautophagy is the major type of autophagy, which includes sequential events of autophagosome formation, autophagosome-lysosome fusion, and autolysosomal degradation of $\operatorname{cargos}^{[4]}$. Autophagy flux is defined as the total dynamics of autophagy and thereby it is the progression of cargo sequestration into autophagosomes, delivery to lysosomes, and degradation by lysosomal enzymes ${ }^{[45]}$. Autophagy flux is usually increased in mechanical injury such as mild traumatic SCI or metabolic stress such as starvation, but autophagy flux is decreased due to suppression of autophagy at an upstream (autophagosome formation) or downstream step (autolysosome formation) ${ }^{[46]}$. Recent studies suggest an impairment of autophagy flux after moderate to severe SCI, which leads to neuronal cell death and adversely affects oligodendrocyte-mediated neuronal myelination and functional recovery ${ }^{[47,48]}$. On the other hand, activating autophagy improves neurological recovery in rodent models of SCI due to activation of autophagosome formation and/or enhancement of autophagy flux ${ }^{[49-51]}$. Although modulation of autophagy plays a crucial role in the pathogenesis in SCI, there is limited knowledge on the role of BMP signaling in the regulation of autophagy after SCI. BMP and activin membrane-bound inhibitor (BAMBI) is a pseudo-receptor that lacks the kinase activity and inhibits the signaling of TGF $\beta$ family ${ }^{[52]}$. BAMBI has been found to be down regulated in rats after SCI, while intraspinal injection of the BAMBI expressing vector after SCI promotes autophagy and improves locomotive function in rats ${ }^{[52]}$. The BAMBI overexpression causes activation of Beclin-1 and LC3B II, two proteins critical for inducing autophagy and maintaining autophagy flux; on the other hand, it results in down regulation of autophagy inhibitor proteins such as Bim and $\mathrm{p}_{2} 2^{[52]}$. The role of BMP ligands and receptors in disruption of autophagy postSCI remains largely unknown; however, modulating BMP signaling to restore autophagy may provide a new therapeutic avenue in treating SCI. 


\section{ROLE OF BMP SIGNALING IN INFLAMMATION AFTER SCI}

Inflammation is encountered in both the acute and chronic phases of SCI and results in expansion of the initial lesion, destruction of nearby tissue, neuronal loss, axonal demyelination, and fibrosis or scar formation ${ }^{[53]}$. Shortly after SCI, there is massive infiltration of neutrophils and after 24 hours, infiltration of reactive microglia/macrophages increases progressively ${ }^{[9]}$. Several weeks following SCI, there is an increase in the infiltration of CD45-positive cells and CD68-positive reactive microglia/macrophages, which mark the phase of chronic inflammation in SCI and are associated with impairment of locomotive function ${ }^{[11]}$. Recent studies suggest contradictory roles of the inhibition of BMP signaling on inflammatory responses after SCI. The transplantation of noggin-expressing NSCs in SCI rats results in a marked increase in macrophage infiltration ${ }^{[16]}$. In contrast, the overexpression of BAMBI in a rat model of SCI results in inhibition of neuroinflammation, which is characterized by reduction in the levels of expression of interleukin (IL)-1 $\beta$, IL-6, IL-10, TGF $\beta$, and mechanistic target of rapamycin ${ }^{[54]}$.

\section{ROLE OF BMP SIGNALING IN NEURONAL AND GLIAL CELL DEATH AFTER SCI}

Both neurons and oligodendrocytes are highly susceptible to cellular damage and death following SCI resulting in axonal demyelination and neurological deficits ${ }^{[7,55]}$. In vitro and in vivo studies have shown that BMP7 exerts beneficial effects on neuronal and oligodendrocyte cell survival ${ }^{[24,56]}$. de Rivero Vaccari et al. ${ }^{[24]}$ studied the protective mechanism of BMP7 on neuronal survival after SCI in vitro and in vivo. BMP7 promotes neuronal survival after SCI in rats and inhibits glutamate induced neuronal cell death in vitro ${ }^{[24]}$. Similarly, Wang et al ${ }^{[56]}$ tested the effects of BMP7 on the survival of oligodendrocytes in vitro. Results showed that BMP7 treatment prevented tumor necrosis factor $\alpha$-induced oligodendrocyte death. These results imply that BMP7 protects neurons and oligodendrocytes from cell death in SCI models. On the other hand, a recent study conducted by Hart et al. ${ }^{[57]}$ has shown that BMP4 induces apoptosis in both neurons and oligodendrocytes via the activation of caspase-3 (the final executioner of apoptosis) after SCI, while its inhibition using BMP signaling inhibitors attenuates the activation of caspase-3. These results suggest different roles of different BMP ligands on neuronal and glial cell survival post-SCI, which requires further investigation.

\section{CONCLUSION AND FUTURE PROSPECTIVE}

BMP ligands, receptors, and inhibitors are differentially expressed in the intact spinal cord in rodents. BMP ligands, receptors, and canonical and non-canonical pathways are upregulated after SCI. In general, augmented BMP signaling results in adverse cellular responses and impairs functional recovery in SCI animal models. On the other hand, the inhibition of BMP signaling improves neuronal cell survival, neuronal outgrowth, and functional recovery after SCI. Although BMP dysregulation is reported in SCI, the cell-type specific role of BMP signaling in SCI remains poorly understood. Several gaps in knowledge still exist regarding the molecular mechanisms underlying BMP dysregulation, the direct causal link between individual BMP ligands and receptors and progression of pathogenesis in SCI, the spatial and temporal effects of BMP signaling in the pathogenesis of acute, subacute, and chronic phases in SCI, and the mechanisms by which BMP ligands regulate autophagy, inflammation, differentiation, and apoptosis. Further in vivo studies using conditional knockout rodent models are needed to understand the specific requirements of different BMP ligands in SCI and neurological recovery, the ligand-receptor pairs that are involved in the regulation of SCI pathogenesis, and the downstream canonical or non-canonical pathways that impact neuronal survival after SCI.

\section{DECLARATIONS}

\section{Authors' contributions}

Conceptualized the theme and conducted the literature review process: Al-Sammarraie $\mathrm{N}$

Contributed to the preparation and revision of the manuscript, interpretation of subtopics, and preparation 
of figures: Al-Sammarraie N, Ray SK

Approved the final version to be published: Al-Sammarraie N, Ray SK

\section{Availability of data and materials}

Not applicable.

\section{Financial support and sponsorship}

The work was supported, in part, by an investigator-initiated research grant (SCIRF-2015-I-01) from the South Carolina Spinal Cord Injury Research Fund (Columbia, SC, USA), an award from the Soy Health Research Program (SHRP, United Soybean Board, Chesterfield, MO, USA), and earlier Ro1 grants (CA091460 and NS-057811) from the National Institutes of Health (Bethesda, MD, USA).

\section{Conflicts of interest}

Both authors declared that there are no conflicts of interest.

\section{Ethical approval and consent to participate}

Not applicable.

\section{Consent for publication}

Not applicable.

\section{Copyright}

(c) The Author(s) 2021.

\section{REFERENCES}

1. Singh A, Tetreault L, Kalsi-Ryan S, Nouri A, Fehlings MG. Global prevalence and incidence of traumatic spinal cord injury. Clin Epidemiol 2014;6:309-31.

2. Musubire AK, Meya DB, Bohjanen PR, Katabira ET, Barasukana P, et al. A systematic review of non-traumatic spinal cord injuries in sub-Saharan Africa and a proposed diagnostic algorithm for resource-limited settings. Front Neurol 2017;8:618.

3. Hagen EM, Rekand T, Gilhus NE, Grønning M. Traumatic spinal cord injuries - incidence, mechanisms and course. Tidsskr Nor Laegeforen 2012;132:831-7.

4. van Middendorp JJ, Goss B, Urquhart S, Atresh S, Williams RP, et al. Diagnosis and prognosis of traumatic spinal cord injury. Global Spine J 2011;1:1-8.

5. Simon F, Oberhuber A. Ischemia and reperfusion injury of the spinal cord: experimental strategies to examine postischemic paraplegia. Neural Regen Res 2016;11:414-5.

6. Marsala M, Sorkin LS, Yaksh TL. Transient spinal ischemia in rat: characterization of spinal cord blood flow, extracellular amino acid release, and concurrent histopathological damage. J Cereb Blood Flow Metab 1994;14:604-14.

7. Alizadeh A, Dyck SM, Karimi-Abdolrezaee S. Traumatic spinal cord injury: an overview of pathophysiology, models and acute injury mechanisms. Front Neurol 2019;10:282.

8. Hassannejad Z, Shakouri-Motlagh A, Mokhatab M, Zadegan SA, Sharif-Alhoseini M, et al. Oligodendrogliogenesis and axon remyelination after traumatic spinal cord injuries in animal studies: a systematic review. Neuroscience 2019;402:37-50.

9. Carlson SL, Parrish ME, Springer JE, Doty K, Dossett L. Acute inflammatory response in spinal cord following impact injury. Exp Neurol 1998;151:77-88.

10. Li N, Leung GK. Oligodendrocyte precursor cells in spinal cord injury: a review and update. Biomed Res Int 2015;2015:235195.

11. Arnold SA, Hagg T. Anti-inflammatory treatments during the chronic phase of spinal cord injury improve locomotor function in adult mice. J Neurotrauma 2011;28:1995-2002.

12. Ray SK, Hogan EL, Banik NL. Calpain in the pathophysiology of spinal cord injury: neuroprotection with calpain inhibitors. Brain Res Rev 2003;42:169-85.

13. Ray SK, Samantaray S, Smith JA, Matzelle DD, Das A, Banik NL. Inhibition of cysteine proteases in acute and chronic spinal cord injury. Neurotherapeutics 2011;8:180-6.

14. Plemel JR, Keough MB, Duncan GJ, Sparling JS, Yong VW, et al. Remyelination after spinal cord injury: is it a target for repair? Prog Neurobiol 2014;117:54-72.

15. Wang RN, Green J, Wang Z, Deng Y, Qiao M, et al. Bone morphogenetic protein (BMP) signaling in development and human diseases. Genes Dis 2014;1:87-105. 
16. Enzmann GU, Benton RL, Woock JP, Howard RM, Tsoulfas P, et al. Consequences of noggin expression by neural stem, glial, and neuronal precursor cells engrafted into the injured spinal cord. Exp Neurol 2005;195:293-304.

17. Horbelt D, Denkis A, Knaus P. A portrait of transforming growth factor $\beta$ superfamily signalling: background matters. Int J Biochem Cell Biol 2012;44:469-74.

18. Heldin CH, Moustakas A. Role of Smads in TGF $\beta$ signaling. Cell Tissue Res 2012;347:21-36.

19. Imamura T, Takase M, Nishihara A, Oeda E, Hanai J, et al. Smad6 inhibits signalling by the TGF- $\beta$ superfamily. Nature 1997;389:622-6.

20. Hanyu A, Ishidou Y, Ebisawa T, Shimanuki T, Imamura T, et al. The N domain of Smad7 is essential for specific inhibition of transforming growth factor-beta signaling. J Cell Biol 2001;155:1017-27.

21. Hata A, Lagna G, Massagué J, Hemmati-Brivanlou A. Smad6 inhibits BMP/Smad1 signaling by specifically competing with the Smad4 tumor suppressor. Genes Dev 1998;12:186-97.

22. Zimmerman LB, De Jesús-Escobar JM, Harland RM. The Spemann organizer signal noggin binds and inactivates bone morphogenetic protein 4. Cell 1996;86:599-606.

23. Matsuura I, Taniguchi J, Hata K, Saeki N, Yamashita T. BMP inhibition enhances axonal growth and functional recovery after spinal cord injury. J Neurochem 2008;105:1471-9.

24. de Rivero Vaccari JP, Marcillo A, Nonner D, Dietrich WD, Keane RW. Neuroprotective effects of bone morphogenetic protein 7 (BMP7) treatment after spinal cord injury. Neurosci Lett 2009;465:226-9.

25. Song P, Xia X, Han T, Fang H, Wang Y, et al. BMSCs promote the differentiation of NSCs into oligodendrocytes via mediating Id 2 and Olig expression through BMP/Smad signaling pathway. Biosci Rep 2018;38:BSR20180303.

26. Sahni V, Mukhopadhyay A, Tysseling V, Hebert A, Birch D, et al. BMPR1a and BMPR1b signaling exert opposing effects on gliosis after spinal cord injury. J Neurosci 2010;30:1839-55.

27. Setoguchi T, Yone K, Matsuoka E, Takenouchi H, Nakashima K, et al. Traumatic injury-induced BMP7 expression in the adult rat spinal cord. Brain Res 2001;921:219-25.

28. Chen J, Leong SY, Schachner M. Differential expression of cell fate determinants in neurons and glial cells of adult mouse spinal cord after compression injury. Eur J Neurosci 2005;22:1895-906.

29. Cui ZS, Zhao P, Jia CX, Liu HJ, Qi R, et al. Local expression and role of BMP-2/4 in injured spinal cord. Genet Mol Res 2015;14:910917.

30. Kim JH, Lee YW, Park YM, Park KA, Park SH, et al. Agmatine-reduced collagen scar area accompanied with surface righting reflex recovery after complete transection spinal cord injury. Spine (Phila Pa 1976) 2011;36:2130-8.

31. Park YM, Lee WT, Bokara KK, Seo SK, Park SH, et al. The multifaceted effects of agmatine on functional recovery after spinal cord injury through Modulations of BMP-2/4/7 expressions in neurons and glial cells. PLoS One 2013;8:e53911.

32. Dmitriev AE, Farhang S, Lehman RA, Ling GS, Symes AJ. Bone morphogenetic protein-2 used in spinal fusion with spinal cord injury penetrates intrathecally and elicits a functional signaling cascade. Spine J 2010;10:16-25.

33. Ahmed S, Gull A, Khuroo T, Aqil M, Sultana Y. Glial cell: a potential target for cellular and drug based therapy in various CNS diseases. Curr Pharm Des 2017;23:2389-99.

34. Okada S, Hara M, Kobayakawa K, Matsumoto Y, Nakashima Y. Astrocyte reactivity and astrogliosis after spinal cord injury. Neurosci Res 2018;126:39-43.

35. Wang H, Song G, Chuang H, Chiu C, Abdelmaksoud A, et al. Portrait of glial scar in neurological diseases. Int J Immunopathol Pharmacol 2018;31:2058738418801406.

36. Wang Y, Cheng X, He Q, Zheng Y, Kim DH, et al. Astrocytes from the contused spinal cord inhibit oligodendrocyte differentiation of adult oligodendrocyte precursor cells by increasing the expression of bone morphogenetic proteins. J Neurosci 2011;31:6053-8.

37. Xiao Q, Du Y, Wu W, Yip HK. Bone morphogenetic proteins mediate cellular response and, together with Noggin, regulate astrocyte differentiation after spinal cord injury. Exp Neurol 2010;221:353-66.

38. Setoguchi T, Nakashima K, Takizawa T, Yanagisawa M, Ochiai W, et al. Treatment of spinal cord injury by transplantation of fetal neural precursor cells engineered to express BMP inhibitor. Exp Neurol 2004;189:33-44.

39. North HA, Pan L, McGuire TL, Brooker S, Kessler JA. $\beta 1$-Integrin alters ependymal stem cell BMP receptor localization and attenuates astrogliosis after spinal cord injury. J Neurosci 2015;35:3725-33.

40. Lü HZ, Wang YX, Zou J, Li Y, Fu SL, et al. Differentiation of neural precursor cell-derived oligodendrocyte progenitor cells following transplantation into normal and injured spinal cords. Differentiation 2010;80:228-40.

41. Karimi-Abdolrezaee S, Billakanti R. Reactive astrogliosis after spinal cord injury-beneficial and detrimental effects. Mol Neurobiol 2012;46:251-64.

42. Parikh P, Hao Y, Hosseinkhani M, Patil SB, Huntley GW, et al. Regeneration of axons in injured spinal cord by activation of bone morphogenetic protein/Smad1 signaling pathway in adult neurons. Proc Natl Acad Sci U S A 2011;108:E99-107.

43. Glick D, Barth S, Macleod KF. Autophagy: cellular and molecular mechanisms. J Pathol 2010;221:3-12.

44. Levine B, Kroemer G. Autophagy in the pathogenesis of disease. Cell 2008;132:27-42.

45. Zhang XJ, Chen S, Huang KX, Le WD. Why should autophagic flux be assessed? Acta Pharmacol Sin 2013;34:595-9.

46. Wong YC, Holzbaur EL. Autophagosome dynamics in neurodegeneration at a glance. J Cell Sci 2015;128:1259-67.

47. Liu S, Sarkar C, Dinizo M, Faden AI, Koh EY, et al. Disrupted autophagy after spinal cord injury is associated with ER stress and neuronal cell death. Cell Death Dis 2015;6:e1582.

48. Saraswat Ohri S, Bankston AN, Mullins SA, Liu Y, Andres KR, et al. Blocking autophagy in oligodendrocytes limits functional recovery after spinal cord injury. J Neurosci 2018;38:5900-12. 
49. Zhou KL, Chen DH, Jin HM, Wu K, Wang XY, et al. Effects of calcitriol on experimental spinal cord injury in rats. Spinal Cord 2016;54:510-6.

50. Zhang D, Xuan J, Zheng BB, Zhou YL, Lin Y, et al. Metformin improves functional recovery after spinal cord injury via autophagy flux stimulation. Mol Neurobiol 2017;54:3327-41.

51. Chen HC, Hsu PW, Tzaan WC, Lee AW. Effects of the combined administration of vitamins C and E on the oxidative stress status and programmed cell death pathways after experimental spinal cord injury. Spinal Cord 2014;52:24-8.

52. Tramullas M, Lantero A, Díaz A, Morchón N, Merino D, et al. BAMBI (bone morphogenetic protein and activin membrane-bound inhibitor) reveals the involvement of the transforming growth factor-beta family in pain modulation. J Neurosci 2010;30:1502-11.

53. Trivedi A, Olivas AD, Noble-Haeusslein LJ. Inflammation and spinal cord injury: infiltrating leukocytes as determinants of injury and repair processes. Clin Neurosci Res 2006;6:283-92.

54. Yang Y, Guo C, Liao B, Cao J, Liang C, He X. BAMBI inhibits inflammation through the activation of autophagy in experimental spinal cord injury. Int J Mol Med 2017;39:423-29.

55. Almad A, Sahinkaya FR, McTigue DM. Oligodendrocyte fate after spinal cord injury. Neurotherapeutics 2011;8:262-73.

56. Wang X, Xu JM, Wang YP, Yang L, Li ZJ. Protective effects of BMP-7 against tumor necrosis factor $\alpha$-induced oligodendrocyte apoptosis. Int J Dev Neurosci 2016;53:10-17.

57. Hart CG, Dyck SM, Kataria H, Alizadeh A, Nagakannan P, et al. Acute upregulation of bone morphogenetic protein-4 regulates endogenous cell response and promotes cell death in spinal cord injury. Exp Neurol 2020;325:113163. 